\title{
Effect of iron on the activation of the MAPK/ERK pathway in PC12 neuroblastoma cells
}

\author{
PABLO MUÑOZ 1 , GABRIELA ZAVALA ${ }^{3}$, KAREN CASTILLO $^{3}$, PABLA AGUIRRE $^{3}$, \\ CECILIA HIDALGO ${ }^{2}$ and MARCO T. NÚNEZZ ${ }^{3}$
}

\begin{abstract}
${ }^{1} \mathrm{PhD}$ Program in Cell, Molecular and Neural Biology, Faculty of Sciences, Universidad de Chile; ${ }^{2}$ Fondap Center for Molecular Studies of the Cell and ${ }^{3}$ Biology Department and Cell Dynamics and Biotechnology Research Center, Faculty of Sciences, Universidad de Chile
\end{abstract}

\begin{abstract}
Recent evidence suggests that reactive oxygen species function as second messenger molecules in normal physiological processes. For example, activation of N-Methyl-D-Aspartate receptor results in the production of ROS, which appears to be critical for synaptic plasticity, one of the cellular mechanisms that underlie learning and memory. In this work, we studied the effect of iron in the activation of MAPK/ERK pathway and on $\mathrm{Ca}^{2+}$ signaling in neuronal PC12 cells. We found that iron-dependent generation of hydroxyl radicals is likely to modulate $\mathrm{Ca}^{2+}$ signaling through RyR calcium channel activation, which, in turn, activates the MAPK/ERK pathway. These findings underline the relevance of iron in normal neuronal function.
\end{abstract}

Key terms: NMDA receptor, calcium, iron, oxidative stress, MAPK/ERK, hippocampal slices, long-term potentiation

\section{INTRODUCTION}

In hippocampal synapses, a rise in intracellular postsynaptic calcium concentration is necessary in order to induce activation of MAPK/ERK pathway and changes in synaptic plasticity. This increase is initially produced by $\mathrm{Ca}^{2+}$ influx through NMDAR. Nevertheless, $\mathrm{Ca}^{2+}$ released from ryanodine-sensitive intracellular stores through $\mathrm{Ca}^{2+}$-induced $\mathrm{Ca}^{2+}$ release amplifies the initial $\mathrm{Ca}^{2+}$ entry signal triggering the activation of a number of signaling cascades, such as the MAPK/ ERK pathway (Krapivinsky et al., 2003). Recent evidence suggests that reactive oxygen species (ROS) function as second messenger molecules in normal physiological processes. For example, activation of N-Methyl-D-Aspartate receptor (NMDAR) results in the production of ROS, which appears to be critical for synaptic plasticity, one of the cellular mechanisms that underlie learning and memory (Bailey et al., 2004; Kahlert et al., 2005). In this work, we studied the effect of iron in the activation of MAPK/ ERK pathway and on $\mathrm{Ca}^{2+}$ signaling in neuronal PC12 cells.

\section{RESULTS AND DISCUSSION}

Given that RyR calcium channels are activated by oxidation (Hidalgo et al., 2000; Donoso et al., 2000; Carrasco et al., 2004), and iron is a notorious ROS producer in neuronal cells (Núñez et al., 2004), we hypothesized that iron-induced ROS could modulate $\mathrm{Ca}^{2+}$ release from $\mathrm{Ry}$-sensitive intracellular stores. To address this possibility, we used confocal imaging in the line-scan mode to detect local $\mathrm{Ca}^{2+}$ signals. When PC12 cells were treated with iron, 
spark-like $\mathrm{Ca}^{2+}$ transients were triggered. This effect was blocked by Ry, a direct indication that the iron-induced $\mathrm{Ca}^{2+}$ sparks were mediated by the RYR calcium channel (Fig. 1).

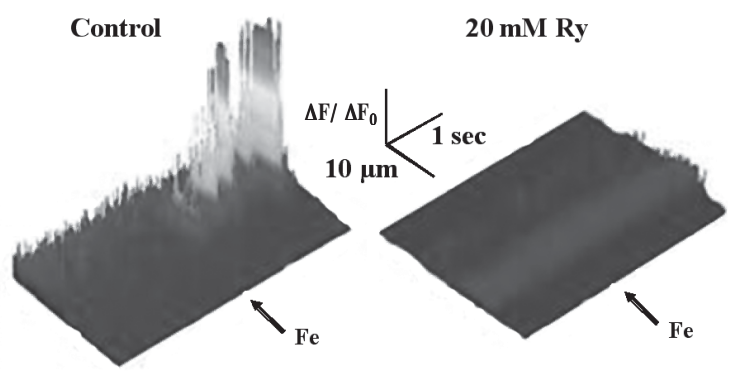

Figure 1. Iron-induced $\mathrm{Ca}^{2+}$ release. Control PC12 cells, or cells pre-treated with $20 \mu \mathrm{M}$ Ry for 1 hour, were loaded with the $\mathrm{Ca}^{2+}$ indicator Fluo 3-AM and then challenged with Fe-NTA (1: 2.2, mol: mol). Confocal line-scan images were taken at a high temporal resolution (2 msec per line) in a LSM 510 confocal microscope equipped with a $\mathrm{CO}_{2^{-}}$and temperature-controlled chamber. Arrows indicate the application of $20 \mu \mathrm{M}$ Fe-NTA.

Since iron activated RyR calcium channels, it was of interest to test if iron could also activate the MAPK pathway. Indeed, iron enhanced ERK1/2 phosphorylation in PC12 cells, in a timeand concentration-dependent form (Fig. 2).

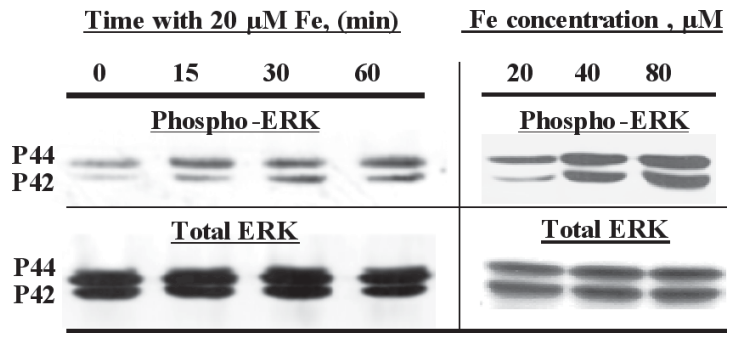

Figure 2. Effect of iron on the expression of total and phospho-ERK1/2. Quantitative Western blot analysis of ERK phosphorylation (upper sections) in PC12 cells exposed to 20 $\mu \mathrm{M}$ Fe-NTA during 1 hour (left sections) or to 20-80 mM Fe for 1 hour (right sections). The membranes were stripped and re-blotted with anti-total ERK (lower sections). P44 and P42 indicate the migration of the $44 \mathrm{KDa}$ and 42 KDa sub-units.
Immunoblot assays with an antibody that recognizes both the phosphorylated and the unphosphorylated forms of ERK $1 / 2$ showed that the observed increases were not due to increased levels of ERK1/2 protein. Treatment of PC12 cells with the iron chelator deferrioxamine or the hydroxyl radical scavenger mannitol attenuated NMDA-induced phosphorylation of ERKs (Muñoz et al., manuscript in preparation). Thus, iron is an effective activator of pre-existing ERK1/2.

In summary, these results suggest that iron-dependent generation of hydroxyl radicals is likely to modulate $\mathrm{Ca}^{2+}$ signaling through RyR calcium channel activation, which, in turn, activates the MAPK/ERK pathway. These findings underline the relevance of iron in normal neuronal function.

\section{ACKNOWLEDGEMENTS}

This work was supported by grants FONDAP CEMC 15010006, MECESUP UCH001, and ICM P99-031F.

\section{REFERENCES}

BAILEY CH, KANDEL ER, SI K (2004) The persistence of long-term memory: A molecular approach to selfsustaining changes in learning-induced synaptic growth. Neuron 44: 49-57

CARRASCO MA, JAIMOVICH E, KEMMERLING U, HIDALGO C (2004) Signal transduction and gene expression regulated by calcium release from internal stores in excitable cells. Biol Res 37: 701-7

DONOSO P, ARACENA P, HIDALGO C (2000) Sulphydryl oxidation overrides $\operatorname{Mg}(2+)$ inhibition of calcium-induced calcium release in skeletal muscle triads. Biophys J 79: 279-286

KAHLERT S, ZUNDORF G, REISER G (2005) Glutamatemediated influx of extracellular $\mathrm{Ca} 2+$ is coupled with reactive oxygen species generation in cultured hippocampal neurons but not in astrocytes. J Neurosci Res 79: 262-271

KRAPIVINSKY G, KRAPIVINSKY L, MANASIAN Y, IVANOV A, TYZIO R, PELLEGRINO C, BEN-ARI Y, CLAPHAM DE, MEDINA I (2003) The NMDA receptor is coupled to the ERK pathway by a direct interaction between NR2B and RasGRF1. Neuron 40: 775-784

HIDALGO C, BULL R, MARENGO JJ, PÉREZ CF, DONOSO P (2000) SH oxidation stimulates calcium release channels (ryanodine receptors) from excitable cells. Biol Res 33: 113-124

NÚÑEZ MT, GALLARDO V, MUÑOZ P, TAPIA V, ESPARZA A, SALAZAR J, SPEISKY H (2004) Progressive iron accumulation induces a biphasic change in the glutathione content of neuroblastoma cells. Free Radic Biol Med 37: 953-960 